NASA Contractor Report 191147
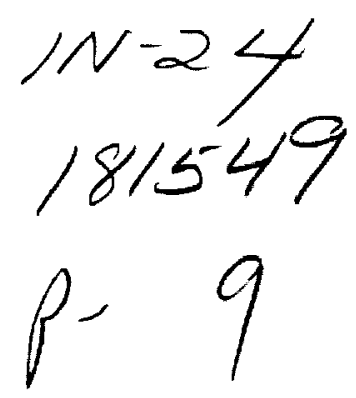

\title{
An Advanced Test Technique To Quantify Thermomechanical Fatigue Damage Accumulation in Composite Materials
}

Michael G. Castelli

Sverdrup Technology, Inc.

Lewis Research Center Group

Brook Park, Ohio

August 1993

Prepared for the

Lewis Research Center

Under Contract NAS3-25266

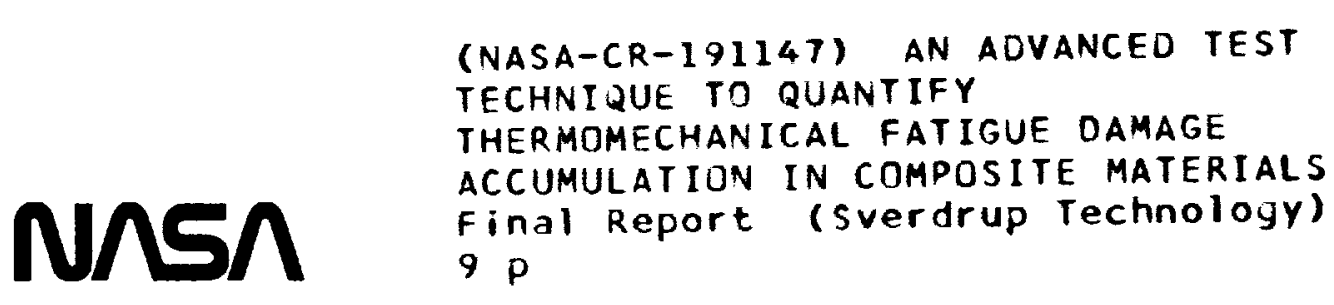

(NASA-CR-191147) AN
TECHNIQUE TO QUANTIFY

THERMOMECHANICAL FATIGUE DAMAGE

ACCUMULATION IN COMPOSITE MATERIALS

$9 \mathrm{p}$
N94-13139

Unclas

$63 / 24 \quad 0181549$ 


\section{$\therefore \quad \cdots$}

I 


\title{
AN ADVANCED TEST TECHNIQUE TO QUANTIFY THERMOMECHANICAL FATIGUE DAMAGE ACCUMULATION IN COMPOSITE MATERIALS
}

\author{
Michael G. Castelli \\ Sverdrup Technology, Inc. \\ Lewis Research Center Group \\ Brook Park, Ohio
}

\begin{abstract}
A mechanical test technique was developed to assist in quantifying the accumulation of damage in composite materials during thermomechanical fatigue (TMF) cycling. This was accomplished by incorporating definitive elastic mechanical property measurements into an ongoing load-controlled TMF test without disturbing the test specimen or significantly altering the test conditions. The technique allows two fundamental composite properties consisting of the isothermal elastic static moduli and the macroscopic coefficient of thermal expansion (CTE) to be measured and collected as functions of the TMF cycles. The specific implementation was incorporated into the commonly employed idealized in-phase and out-of-phase TMF cycles. However, the techniques discussed could be easily implemented into any form of load-controlled TMF mission cycle. By quantifying the degradations of these properties, tremendous insights are gained conceming the progression of macroscopic composite damage and often times the progression of damage within a given constituent. This information should also be useful for the characterization and essential for the verification of analytical damage modeling methodologies. Several examples utilizing this test technique are given for three different fiber lay-ups of titanium metal matrix composites.
\end{abstract}

\section{INTRODUCTION}

Many types of advanced composite materials are currently being evaluated for high-temperature airframe and propulsion system applications. These materials include polymer, metal, and ceramic matrix composite systems (PMCs, MMCs, and CMCs, respectively). As the vast majority of potential applications involve an assortment of cyclic stress and temperature conditions, it is prudent to evaluate the material's response under thermomechanical fatigue (TMF) loading conditions.

Among the many technical challenges associated with researching a composite material's TMF behavior, one clear difficulty which often tends to be overlooked is the process by which the TMF test data is analyzed and interpreted. That is, if the data is going to be used for anything beyond the basic life parameter, $N_{f}$, it is crucial to be aware of the real-time components of stress, mechanical strain, and thermal strain. This is particularly important for composite material test data, where the thermal strain characteristics can potentially change as a function of composite and constituent damage. For example, if an accurate data analysis of TMF deformation is required, it is not sufficient to assume that the composite's coefficient of thermal expansion (CTE) will remain unaltered throughout the course of the test, as this macroscopic property is a function of internal damage state, residual stresses, inelastic work, etc. [this work, 1]. Without the real-time CTE, the material's true mechanical strain response cannot be ascertained from the total strain data.

The inherent complexities associated with TMF deformation and life data make it ideal for the verification of an analytical model. Unfortunately, many of these same complexities often make the data less than ideal for purposes of analytical model characterization. This is particularly the case for deformation and damage modeling. For example, in contrast to an isothermal fatigue test, a fundamental material property such as the elastic static modulus $(E)$ cannot be obtained from the deformation data during a TMF test because of the continuously changing temperature. Thus, if a quantitative assessment of stiffness degradation was required for the purposes of cyclic damage characterization, this information could not be directly obtained from basic inphase or out-of-phase TMF tests such as those defined in Figure 1. 
In an effort to circumvent these shortcomings, a specialized testing technique was developed. First, the improved technique enables definitive assessment of real-time mechanical and thermal strain components throughout the course of a TMF test, and second, the test procedure assists in quantifying the accumulation of damage in composite materials during TMF testing. This advance was accomplished by incorporating fully automated elastic mechanical property measurements into an ongoing TMF test without disturbing the test specimen or significantly altering the test conditions. The testing procedure allows two key composite properties consisting of the isothermal $E$ values and the CTE to be measured and collected as functions of the TMF cycles.

\section{TEST METHODOLOGY AND TECHNIQUE}

As a simplification of prototypical TMF loading conditions, idealized 0-degree in-phase and 90-degree out-ofphase (hereafter referred to as IP and OP, respectively) cyclic mechanical load/temperature histories are commonly utilized for coupon-level composite specimen testing. Such idealizations allow for full thermomechanical loadings in the context of relatively simple and potentially well controlled conditions. Also, these idealized cycles subject the material to a straightforward TMF history, enhancing the data's value for purposes of analytical and numerical model characterization and verification. With this in mind, and given that the vast majority of advanced high temperature composites are tested uniaxially, utilizing flat-plate coupon specimen designs, the discussion of the test methodology and technique will be limited to load-controlled IP and OP TMF testing. However, the techniques could easily be incorporated into any form of load-controlled TMF mission cycle.

The general test methodology for quantifying both the stiffness and the CTE degradation during TMF testing is shown graphically in Figure 2. Two deformation cycles are shown from a zero-tension IP TMF test on a $\left[0^{\circ} / 90^{\circ}\right]_{s}$ titanium MMC. The test procedure is uncomplicated and requires little by way of explanation. After each TMF cycle designated for data collection, the specimen is subjected to a thermal cycle identical to that employed in the TMF test, but the load is maintained at zero. The thermal cycle is represented by the horizontal line from $T_{1}$ to $T_{2}$ at zero load. This thermal cycle allows the real-time or "current" thermal strain characteristics of the composite to be explicitly measured with the high temperature extensometer mounted on the specimen, in turn allowing the composite's instantaneous and mean CTE values to be determined. Note that this half-cycle from $T_{1}$ to $T_{2}$ is sufficient to obtain the current thermal strain characteristics of the material. This data may also be collected during the corresponding half-cycle from $T_{2}$ to $T_{1}$. However, the two measurements may vary slightly depending upon the difference in gage-section thermal gradients during the two half-cycles. Ideally, the temperature gradient over the gage-section should be minimized.

There is potential for some strain recovery to occur in the composite during the thermal cycle at zero load, particularly if a high degree of strain ratchetting has occurred during the course of the test. As a safeguard to minimize the effects of this strain response on the CTE measurements, it may be necessary to subject the specimen to two thermal cycles, neglecting the first and collecting the thermal strain characteristics from the second. Experience with MMCs used to verify this technique has shown that the vast majority of short-term strain recovery occurs during the first thermal cycle, allowing subsequent cycles to essentially reflect the current thermal strain characteristics of the composite. This behavior will vary with each composite system, depending upon the system's thermal recovery behavior.

At the extreme of the thermal cycle (i.e. $T_{2}$ ), the temperature is briefly stabilized. Note that the specimen is still at zero load and thus the potential for unwanted material strain-creep to occur is essentially eliminated. A small elastic load is applied to ascertain the material's current isothermal $E$ (i.e. stiffness) at $T_{2}$; this value is represented by the stress-strain line marked $E_{2}$ on Figure 2. The thermal cycle then proceeds to the value of $T_{1}$ at which point the temperature is again stabilized and the current isothermal $E$ at $T_{1}$ is obtained. At this point the full TMF cycle is re-initiated and the test proceeds until the next cycle designated for data collection is reached. Note that the magnitude of the elastic load applied to obtain E should be selected sufficiently "small" so as not to introduce additional material damage.

In comparison to a standard TMF test without the property measurements, this technique introduces several additional thermal cycles at zero load and several relatively small elastic loads. These additional loadings were found to be inconsequential with respect to the ongoing material damage and resulting TMF life. This was verified throughout the development and implementation of this test methodology by comparing fatigue lives of MMC test specimens with and without the additional property measurements. No differences were distinguish. There are several benefits realized from this technique. First, the "real-time" thermal strain information is 
essential if an accurate mechanical strain response is to be obtained from a post-test analysis of the deformation behavior. Second, the CTE and isothermal E measurements provide a definitive quantitative measurement for tracking the TMF damage progression. In addition to the advantages these data provide for analytical model characterization and verification, important information is also provided to assist in defining specimen damagestate or effective material failure. Measurement of the isothermal $E$ values enables direct comparisons with data obtained from isothermal fatigue tests, facilitating stiffness degradation/damage comparisons between TMF and isothermal fatigue loadings. Lastly, as the following examples will attest, insight can be gained concerning the ongoing composite damage mechanisms.

\section{TEST VERIFICATION AND EXAMPLES}

Having implemented the test techniques for measuring the degradation of the E values and CTE during TMF cycling, typical results are given for titanium metal matrix composites featuring three different fiber lay-ups. As the focus of this discussion is to illustrate the types and benefits of information collected by the improved test methodology, a detailed discussion and analysis of the data will not be given here, but rather references will be cited as appropriate.

Shown in Figure 3 are the isothermal $E$ measurements collected for a $\left[0^{\circ}\right]_{4}$ titanium MMC during OP TMF cycling. The two sets of data represent the isothermal $E$ values corresponding to the temperature extremes of the TMF cycle. Several key observations can be made concerning the damage accumulation. Note that the $E_{150^{\circ} \mathrm{C}}$ values do not degrade similarly to those measured at $650^{\circ} \mathrm{C}$, and further, the $E_{150^{\circ} \mathrm{C}}$ values degrade to a level well below those measured at $650^{\circ} \mathrm{C}$. This somewhat unexpected result reveals that with increasing OP TMF damage, the composite material is actually less stiff at lower temperatures over this temperature range. Previous work has shown that the dominant damage mechanism in a $\left[0^{\circ}\right]$ titanium MMC under OP TMF loading is matrix cracking in the absence of fiber damage [2]. Given extensive matrix cracking, and considering the relatively high tensile residual stresses in the matrix at low temperatures, it is reasonable to assume that the matrix cracks are being held open at low temperatures, and thus promoting a less stiff response, relative to the high temperature $\mathrm{E}$ measurements. In terms of the composite properties, this effect is obviously strong enough to override the natural trends for the constituent stiffnesses to decrease with increasing temperature, such as that exhibited at the onset of the test. Clearly, this improved TMF test methodology is capable of adding tremendous insights into the damage states evolving in composite materials.

Shown in Figure 4 are the mean CTE measurements (i.e. $\left(\Delta \varepsilon_{150-650^{\circ}}\right) / 500^{\circ} \mathrm{C}$ ) obtained for the OP TMF test discussed in Figure 3. For this combination of material and test conditions, the thermal strain characteristics of the composite change dramatically as a function of accumulated TMF damage. This is revealed by a $25 \%$ drop in mean CTE before specimen failure occurred. This effect can be completely hidden within the total strain measurements as a result of the ongoing increase in the composite's compliance. That is, the mechanical component of strain is increasing with damage accumulation, and the thermal component of strain is decreasing with damage accumulation. Without the explicit measurement of the real-time thermal strain characteristics, an accurate post-test decomposition of the total strain into mechanical and thermal components is essentially impossible. Thus, for purposes of numerical or analytical deformation and damage model characterization, and in particular, model verification, the improved test technique provides essential information.

Shown in Figures 5 and 6 are the isothermal E values and mean CTE values, respectively, collected during IP TMF cycling of a $\left[90^{\circ}\right]_{8}$ titanium MMC [3]. As seen in the $\left[0^{\circ}\right] \mathrm{MMC}$, the E values recorded at the temperature cycle extremes do not degrade in identical fashion. For the $\left[90^{\circ}\right] \mathrm{MMC}$, the high temperature $\mathrm{E}$ values tended to degrade earlier in life, as illustrated by the data given in Figure 5 . Also note the significant stiffness loss after only one TMF cycle. This is typically associated with fiber/matrix debonding in the load direction.

Data collected by this improved test methodology indicate that as TMF damage progresses in the composite, the mean CTE (and instantaneous CTE) in the $\left[90^{\circ}\right]$ direction will increase. This trend may be surprising; however, this response may be qualitatively understood by examining a rule of mixtures approach to the composite CTE in the transverse direction. Schapery [4] has derived the expression for $\mathrm{CTE}_{190]}$, yielding:

$$
\mathrm{CTE}_{[90]}=\left(1+v_{f}\right) \operatorname{CTE}_{\mathrm{f}} \mathrm{V}_{\mathrm{f}}+\left(1+v_{\mathrm{m}}\right) \mathrm{CTE}_{\mathrm{m}} \mathrm{V}_{\mathrm{m}}-\mathrm{CTE}_{\mathrm{L}} \mathrm{v}_{\mathrm{L}}
$$

where $v$ and $V$ are the Poisson's ratio and volume fraction, respectively, and subscripts $f, m$, and $L$ represent the fiber, the matrix, and composite longitudinal direction, respectively. If the ensuing damage introduces a decrease 
in the restraint along the composite's longitudinal direction (i.e. the last term decreases), it can be seen from the equation above that the $\mathrm{CTE}_{190]}$ will increase. The data clearly supports this scenario and further, assists in quantifying the ensuing composite TMF damage.

In a format similar to the previous data graphs, Figures 7 and 8 reveal the $E$ and mean CTE degradation for a $\left[0^{\circ} / 90^{\circ}\right]_{\text {s }}$ titanium MMC subjected to OP TMF loading conditions [5]. As with the other fiber lay-ups discussed, this unique data is very revealing concerning the quantification of damage accumulation. Note again that the $E$ values do not degrade equally, but rather, the low temperature $E$ values degrade much more severely. Qualitative information gleaned from fractography and metallography [5], indicated that debonding of the $90^{\circ}$ fibers and environment enhanced matrix fatigue cracking were the primary damage mechanisms with little or no $0^{\circ}$ fiber damage. From a simple rule of mixtures standpoint, the matrix's contribution to the composite $\mathrm{E}$ values is much greater at $150^{\circ} \mathrm{C}$ than at $650^{\circ} \mathrm{C}$. This comes from the fact that the Timetal $21 \mathrm{~S}$ matrix E values are strongly dependent upon temperature in this temperature range, unlike the SCS-6 fiber E values. Given this fact, and considering the extensive matrix damage in the absence of $0^{\circ}$ fiber damage, the composite $\mathrm{E}_{150^{\circ} \mathrm{C}}$ values will degrade to a greater extent than the composite $E_{650^{\circ} \mathrm{c}}$ values as quantitatively characterized by the data represented.

Figure 8 illustrates that the mean CTE reflects some extent of damage after the first TMF cycle. This is most likely related to debonding of the $90^{\circ}$ fibers. With continued cycling, one can see that the thermal strain characteristics of the MMC change dramatically, as the mean value degrades $23 \%$ before failure occurs. Again, in light of the first order affect of the thermal strain component on the total measured strain, this observation reinforces the importance of measuring the current CTE.

\section{A TEST CONTROL ISSUE}

A final point which needs to be made is the implications these data have on strain-controlled testing of composite materials. It is clearly illustrated from the data above that the thermal strain characteristics of composites can change as functions of composite damage. If the TMF tests are conducted under load-controlled conditions, such as those discussed above, the changing CTE becomes an important issue for accurate post-test data reduction. It is not, however, an issue affecting test control, as the changing CTE will not affect the force measurements made by the load cell utilized for the closed-loop control commands. In contrast, if the TMF tests are conducted under strain-controlled conditions, the changing CTE becomes an important issue for accurate test control. Under these conditions, the changing CTE will affect the total strain measurements made by the extensometer which are utilized for the closed-loop control commands. The total TMF strains and strain range must be appropriately adjusted throughout the test to account for the changing CTE. Otherwise, the mechanical strain and strain range imposed upon the specimen will also be changing throughout the test. Further, the impact of a changing thermal strain component must also be considered for strain-controlled isothermal tests, as this may introduce an unwanted shift in the mechanical mean strain.

\section{SUMMARY AND CONCLUSIONS}

An advanced test methodology and technique was developed and successfully implemented to assist in quantifying the accumulation of thermomechanical fatigue (TMF) damage in composite materials. This method incorporates definitive isothermal elastic static moduli (E) and coefficient of thermal expansion (CTE) measurements into an ongoing TMF test without disturbing the test specimen or significantly altering the test conditions. Verification of this technique was performed on three different fiber lay-ups of titanium metal matrix composites utilizing commonly employed in-phase and out-of-phase TMF cycles.

Results from all the cases examined clearly indicate several conclusions:

1) Measurements of the real-time isothermal $E$ and CTE provide a clear quantitative means for tracking TMF damage progression.

2) A composite's macroscopic CTE and E can change significantly as functions of TMF damage.

3) Assessment of a composite's real-time macroscopic thermal strain response, such as that recorded by the advanced test technique, is essential for accurate post-test analyses of the TMF deformation behavior.

4) Because a composite material's macroscopic thermal strain characteristics can change as a function of damage, increased discretion must be used when fatigue testing is conducted under strain-controlled conditions. 


\section{ACKNOWLEDGEMENTS}

The author wishes to acknowledge Mr. Chris Burke for his diligent assistance conducting the high temperature fatigue experiments at the NASA Lewis Fatigue and Structures Laboratory.

\section{REFERENCES}

1. Urguhart, E., Arnold, S.M., Pindera, M.J. and Aikin, BJ., "Simulation of Experimentally Observed Thermal Expansion Behavior of FeCrAlY-Based Composites," presented at HITEMP Review 1993: Advanced High Temperature Engine Materials Technology Program, NASA Lewis Research Center, Oct., 1993.

2. Castelli, M.G., Bartolotta, P.A. and Ellis, J.R., "Thermomechanical Testing of High-Temperature Composites: Thermomechanical Fatigue Behavior of SiC(SCS-6)/Ti-15-3," Composite Materials: Testing and Design (Tenth Volume), ASTM STP 1120, Glen C. Grimes, Ed., Philadelphia, 1992, pp. 70-86.

3. Castelli, M. G., "Thermomechanical Fatigue Behavior of a [90] $]_{8}$ SCS-6/Ti-15-3 Composite," HITEMP Review 1992: Advanced High Temperature Engine Materials Technology Program, NASA CP-10104, vol. 2, Oct. 1992, pp. 52:1-14. (Available from the Center for Aerospace Information as 93X10284.)

4. Schapery, R.A.,"Thermal Expansion Coefficients of Composite Materials Based on Energy Principles," $J$. of Composite Materials, 2 (3), 1968, pp. 380-404.

5. Castelli, M. G., "Thermomechanical Fatigue Damage/Failure Mechanisms in SCS-6/Timetal 21S [0/90], Composite," NASA CR-19115, 1993.

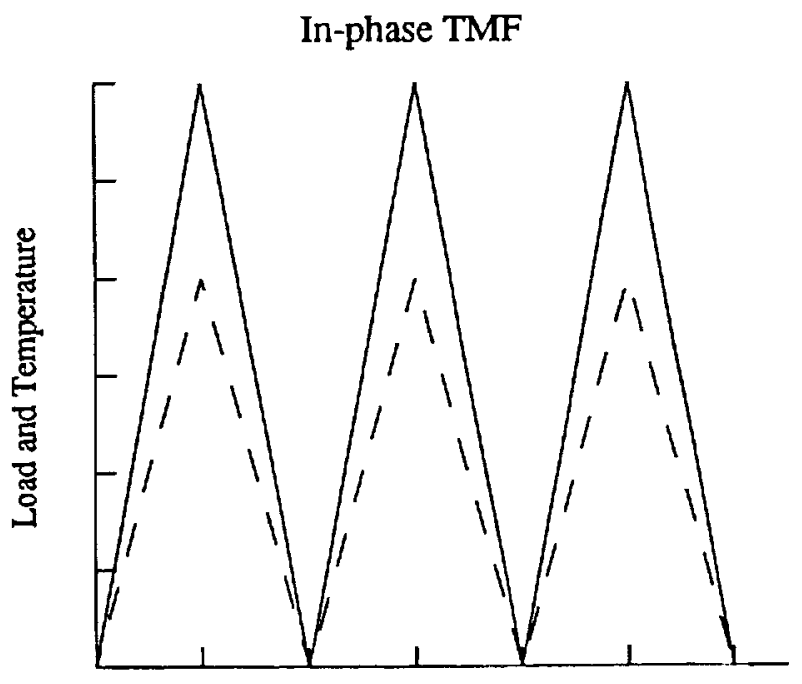

Time
Out-of phase TMF

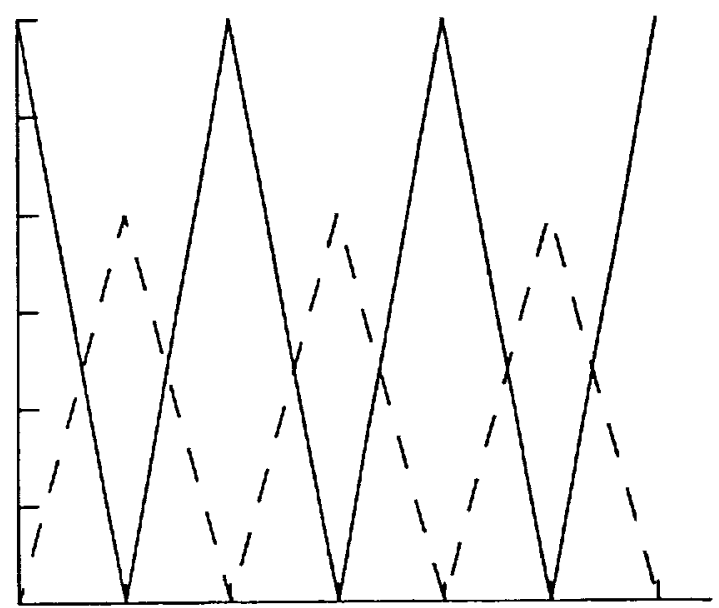

Time

Figure 1.-Test definition for load-controlled in-phase and out-of-phase thermomechanical fatigue tests. 


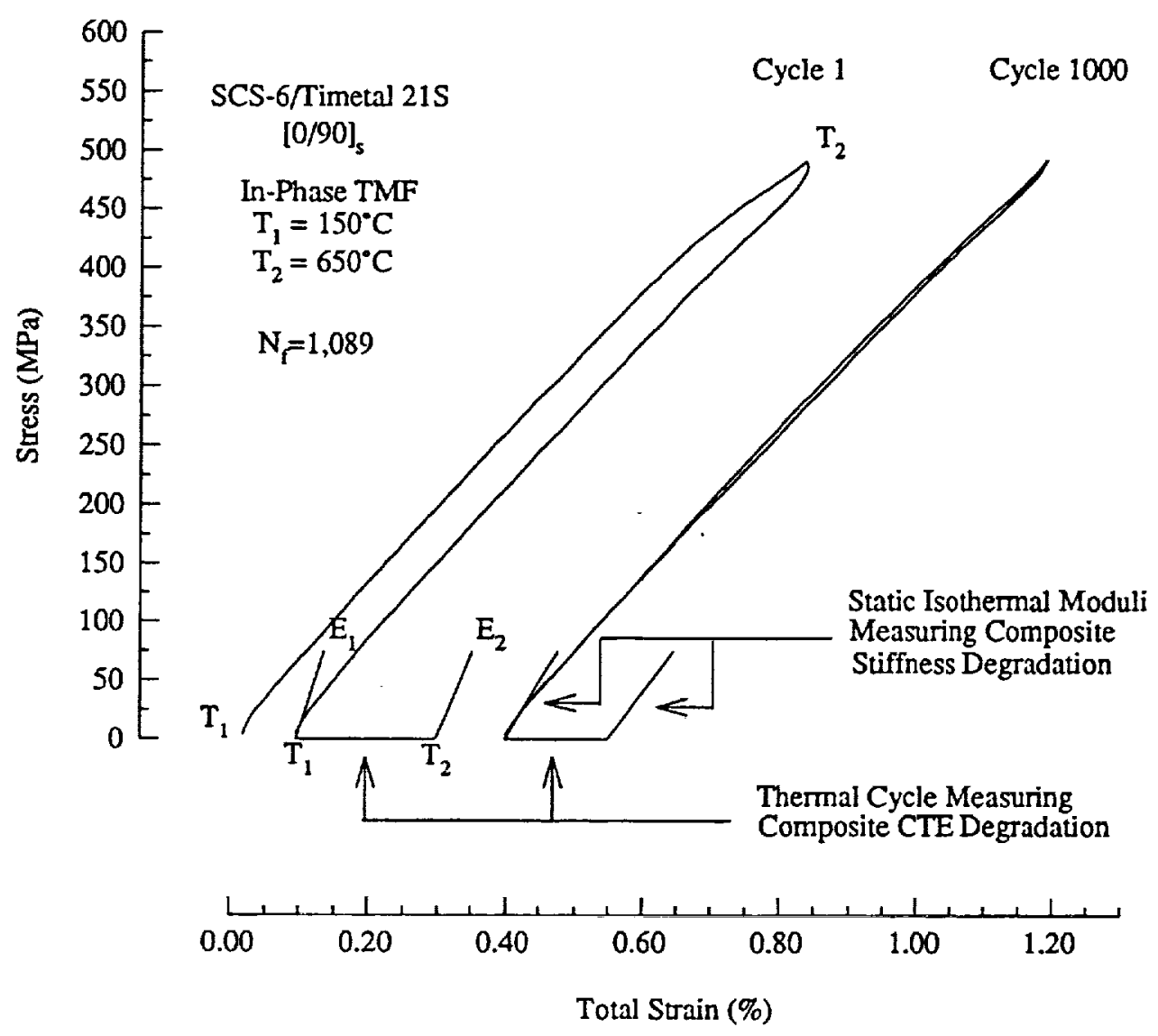

Figure 2.-Improved test methodology enabling definitive quantification of thermomechanical fatigue damage progression.

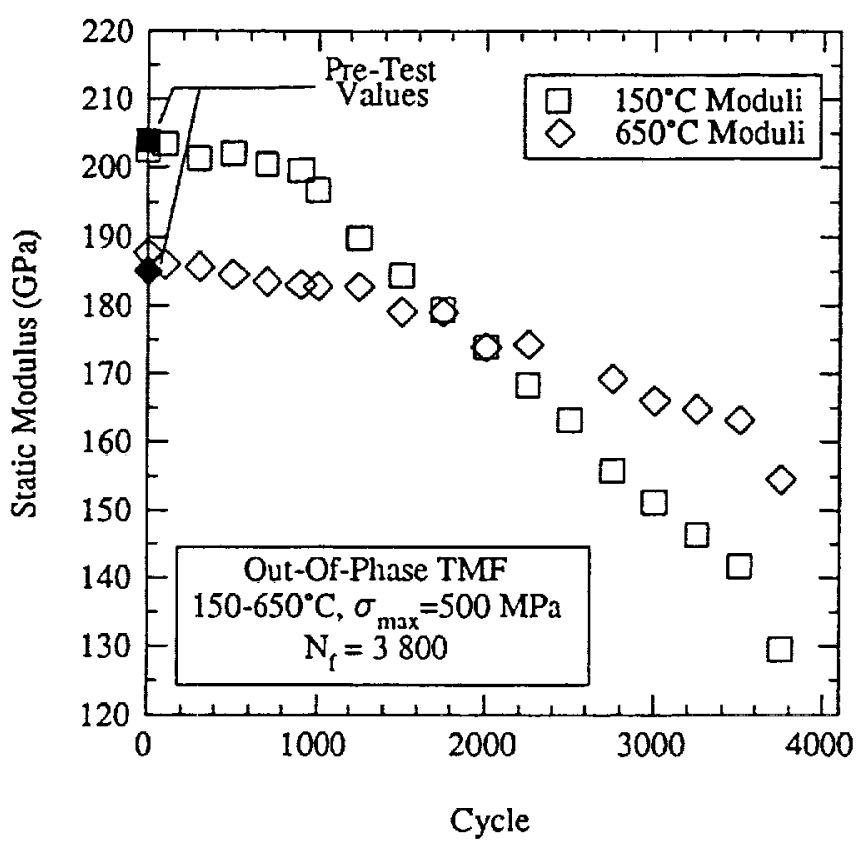

Figure 3.-Thermomechanical fatigue degradation of the isothermal static moduli; SCS-6/Timetal $21 \mathrm{~S}[0]_{4}$.

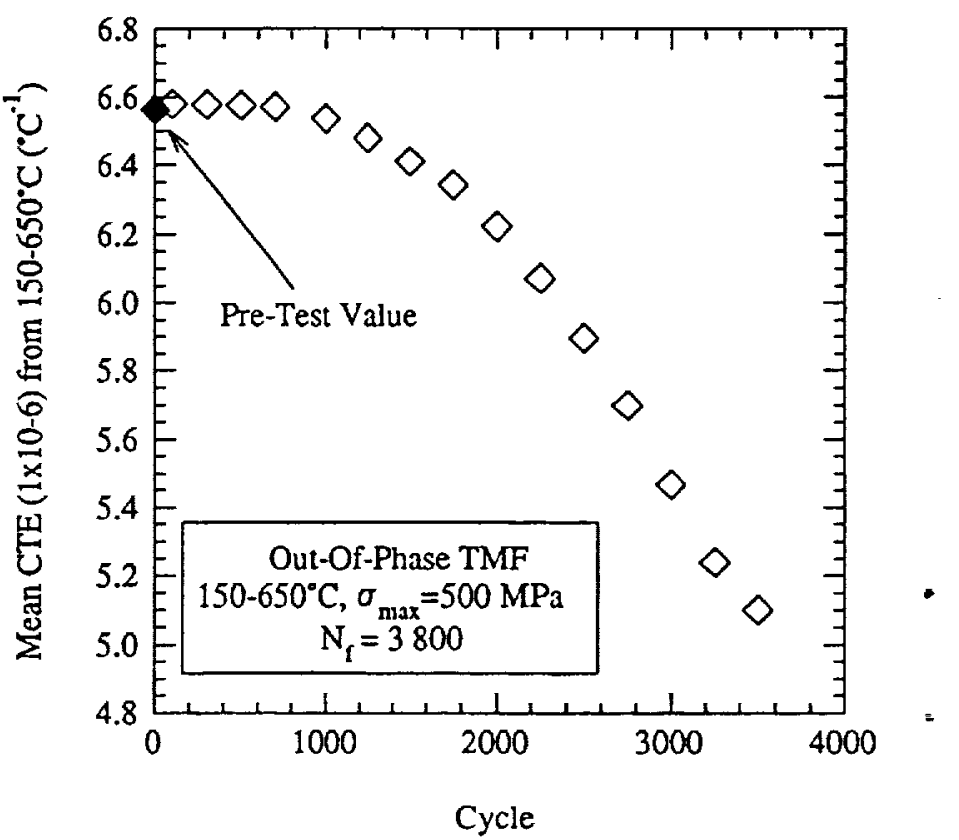

Figure 4.-Thermomechanical fatigue degradation of the mean coefficient of thermal expansion; SCS-6/Timetal $21 \mathrm{~S}[0]_{4}$. 


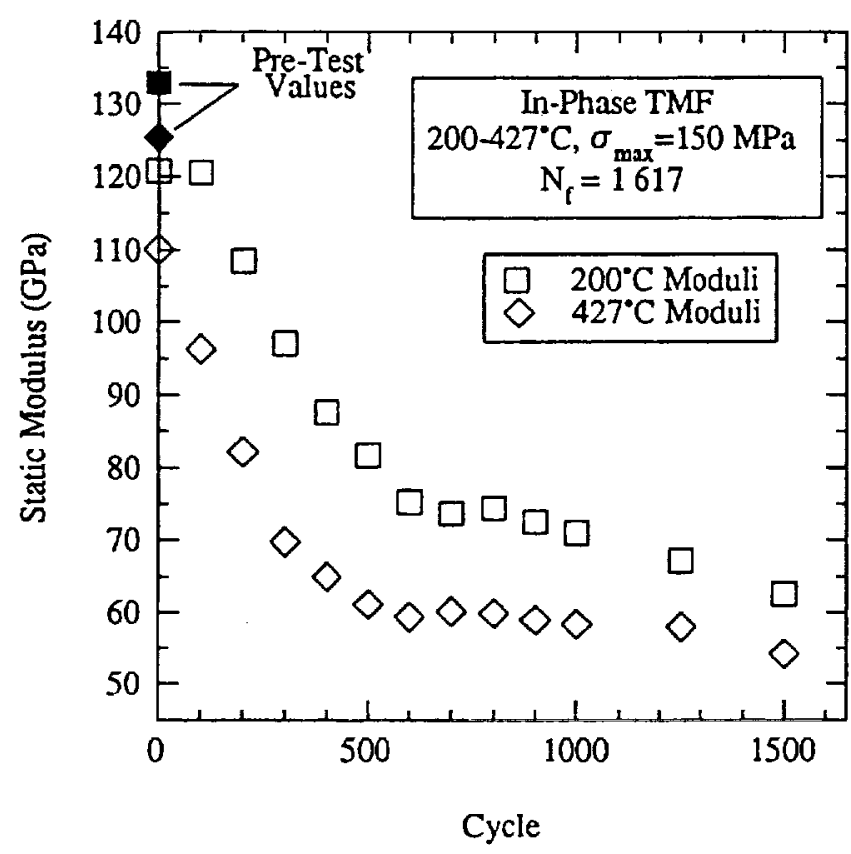

Figure 5.-Thermomechanical fatigue degradation of the isothermal static moduli; SCS-6/Ti-15-3 $[90]_{8}$.

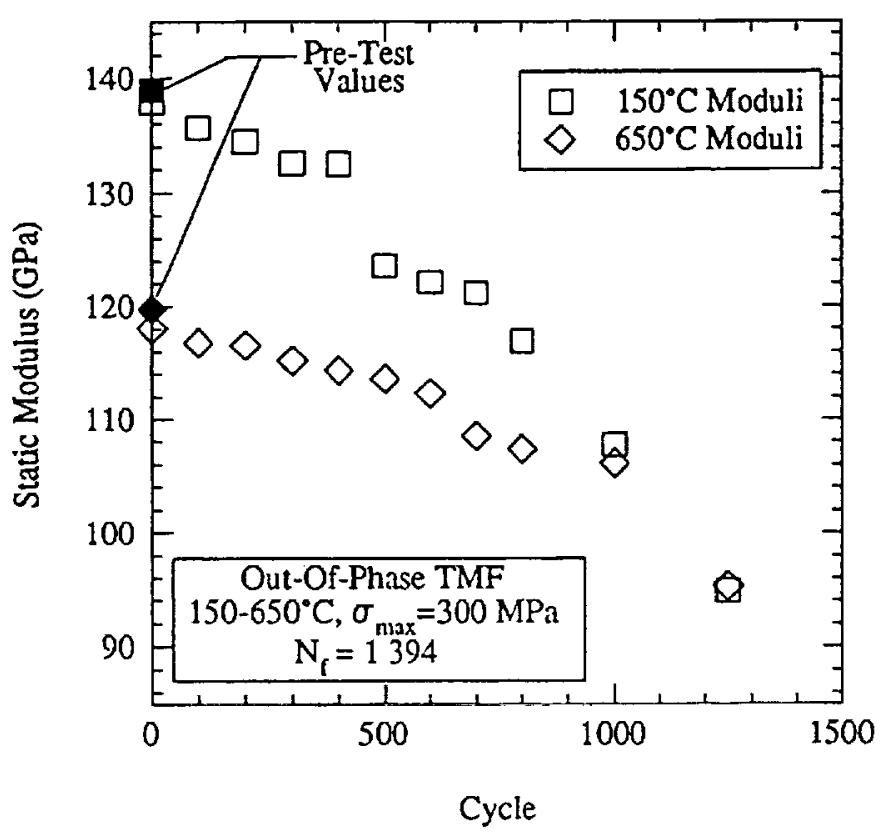

Figure 7.-Thermomechanical fatigue degradation of the isothermal static moduli; SCS-6/Timetal $21 \mathrm{~S}[0 / 90]_{s^{*}}$.

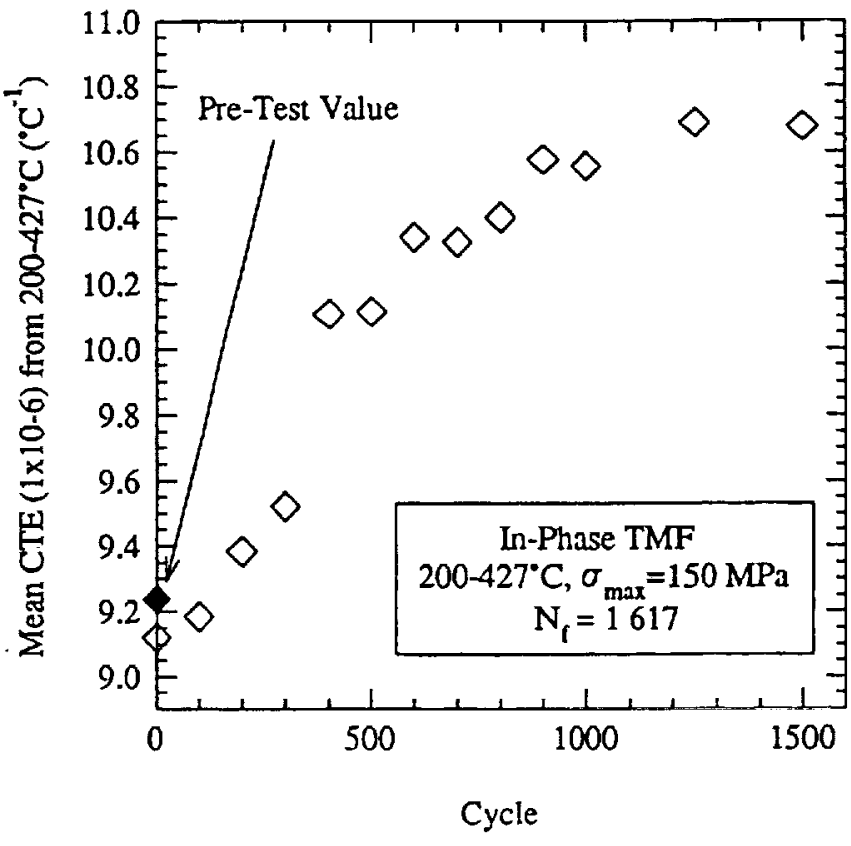

Figure 6.-Thermomechanical fatigue degradation of the mean coefficient of thermal expansion; SCS-6/Ti-15-3 $[90]_{8}$.

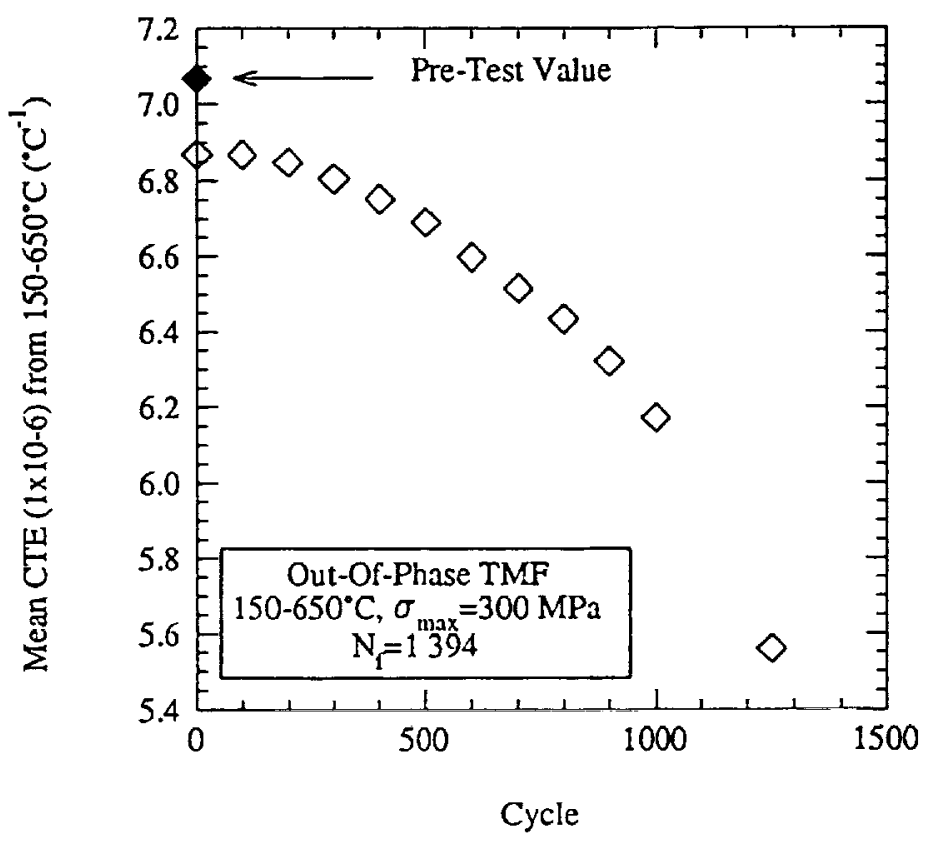

Figure 8.-Thermomechanical fatigue degradation of the mean coefficient of thermal expansion; SCS-6/Timetal $21 \mathrm{~S}[0 / 90]_{s}$. 
Public reporting burden for this collection of information is estimaled to average 1 hour per response, including the time for reviewing instructions, searching existing data sources, gathering and maintaining the data needed, and completing and reviewing the collection of information. Send comments regarding this burden estimate or any other aspect of this collection of information, including suggestions for reducing this burden, to Washington Headquarters Servicas, Directorate for Information Operations and Reports, 1215 Jefferson Davis Highway, Suite 1204, Arlington, VA 22202-4302, and to the Office of Management and Budget, Paperwork Peduction Project (0704-0188), Washington, DC 20503.

\begin{tabular}{|l|l|r|}
\hline 1. AGENCY USE ONLY (Lave blank) & $\begin{array}{c}\text { 2. REPORT DATE } \\
\text { August } 1993\end{array}$ & $\begin{array}{r}\text { 3. REPORT TYPE AND DATES COVERED } \\
\text { Final Contractor Report }\end{array}$
\end{tabular}

4. TITLE AND SUBTITLE

An Advanced Test Technique To Quantify Thermomechanical Fatgue Damage Accumulation in Composite Materials

\section{AUTHOR(S)}

Michael G. Castelli

7. PEERFORMING ORGANZATION NAME(S) AND ADDRESS(ES)

Sverdrup Technology, Inc.

Lewis Research Center Group

2001 Aerospace Parkway

Brook Park, Ohio 44142
5. FUNDING NUMBERS
9. SPONSORING/MONITORING AGENCY NAME(S) AND ADDRESS(ES)

National Aeronautics and Space Administration

Lewis Research Center

Cleveland, Ohio 44135-3191
WU-510-01-50

C-NAS3-25266
8. PERFORMING ORGANIZATION REPORT NUMBER

E-8068

11. SUPPLEMENTARY NOTES

Project Manager, J. Rod Ellis, Structures Division, (216) 433-3340, NASA Lewis Research Center.

12a. DISTRIBUTION/AVALABILITY STATEMENT

12b. DISTAIBUTION CODE

Unclassified - Unlimited

Subject Category 24

13. ABSTRACT (Maximum 200 words)

A mechanical test technique was developed to assist in quantifying the accumulation of damage in composite materi als during thermomechanical fatigue (TMF) cycling. This was accomplished by incorporating definitive elastic mechanical property measurements into an ongoing load-controlled TMF test without disturbing the test specimen or significantly altering the test conditions. The technique allows two fundamental composite properties consisting of the isothermal elastic static moduli and the macroscopic coefficient of thermal expansion (CTE) to be measured and collected as functions of the TMF cycles. The specific implementation was incorporated into the commonly employed idealized in-phase and out-of-phase TMF cycles. However, the techniques discussed could be easily implemented into any form of load-controlled TMF mission cycle. By quantifying the degradations of these properties, tremendous insights are gained concerning the progression of macroscopic composite damage and often times the progression of damage within a given constituent. This information should also be useful for the characterization and essential for the verification of analytical damage modeling methodologies. Several examples utilizing this test technique are given for three different fiber lay-ups of titanium metal matrix composites.

\begin{tabular}{|c|c|c|}
\hline 14. SUBJECT TERMS \\
Composite testing; Thermomechanical fatigue; Damage behavior; Test techniques \\
\hline $\begin{array}{c}\text { 17. SECURITY CLASSIFICATION } \\
\text { OF REPORT } \\
\text { Unclassified }\end{array}$ & $\begin{array}{c}\text { 18. SECURIT CLASSIFICATION } \\
\text { OF THIS PAGE } \\
\text { Unclassified }\end{array}$ & $\begin{array}{c}\text { 19. SECURTY CLASSIFICATION } \\
\text { OF ABSTRACT } \\
\text { Unclassified }\end{array}$ \\
\hline
\end{tabular}

